\title{
Sizing up Australia: toward a national sizing survey
}

\author{
Daisy Veitch ${ }^{\mathrm{a}, *}$, Verna Blewett ${ }^{\mathrm{b}}$ and David Caple ${ }^{\mathrm{c}}$ \\ a*SHARP Dummies Pty Ltd, 102 Gloucester Avenue, Belair, South Australia 5052, Australia \\ ${ }^{b}$ Appleton Institute, Central Queensland University, 44 Greenhill Rd, Wayville, South Australia 5034, Australia \\ ${ }^{\mathrm{c}}$ David Caple \& Associates, PO Box 2135, East Ivanhoe, Victoria 3079, Australia
}

\begin{abstract}
This paper reports on the outcomes of research on the use of anthropometric data by designers of Australian workplaces and products used in Australian workplaces. Australian designers were asked how they used anthropometric data, and about the adequacy of data that were available to them for their needs as designers. In addition to a review of published and grey literature, designers were surveyed and asked for detailed information about their use of anthropometric data and about their needs. Thirty-two completed questionnaires were received. Two focus groups of designers were conducted; 13 people attended in Adelaide and 16 in Melbourne. The data indicated that designers either did not use anthropometric data at all or had difficulty finding data that were reliable and relevant to their specific needs. In response to the findings the Human Factors and Ergonomics Society of Australia developed a Special Interest Group for anthropometry that currently has over 150 members. The Group is actively lobbying government for an Australian Sizing Survey, so this research is an important stimulus to a major policy investment for Australia.
\end{abstract}

Keywords: Engineering anthropometry, human factors, workplace design, product design, sizing survey

\section{Introduction}

This research was sponsored by the Australian Safety and Compensation Council (ASCC) [now called Safe Work Australia] as the primary policy body for work health and safety (WHS) in Australia. [13] The Council recognized the vital importance of the design of products and workplaces to improving WHS. National WHS legislation (due to come into effect in January 2012) places considerable onus on designers to consider WHS in order to prevent workrelated illness and injury and contribute to improved health and safety at work. To achieve this, designers require accurate information to create safe designs, but there is no anthropometric database of the Australian workforce.

\subsection{Different uses of anthropometric data}

There are four main uses of anthropometric data and their end use or purpose determines the suitabili- ty and relevance of these data to satisfactorily achieve a useful outcome. The main uses are:

1) biological anthropology (often uses Martin's Technique for data collection), [10]

2) sports science (often uses The International Society for the Advancement of Kinanthropometry (ISAK) methods for data collection), [11]

3) medicine and public health (often uses waist circumference, height, weight and BMI measures as the data collected) [2, 3] and,

4) engineering and design (often uses Civilian American and European Surface Anthropometry Resource (CAESAR) method for data collection). [4]

Each of these forms of anthropometry uses different measurement techniques, and uses the data differently and for different purposes. [7, 8] Thus, not all 'anthropometric data' are suitable for engineering and design purposes.

\footnotetext{
*Daisy Veitch. Email: daisy@sharpdummies.com.au
} 


\subsection{Engineering and design anthropometry}

Engineering and design anthropometry, which is the form considered in this paper, obtains data that are different from the other forms of anthropometry. Biological anthropometry relies on measurements of skeletal remains and amongst other things, tries to project from these data for comment on human evolution. Such data have specific uses, but are not particularly relevant for the design of equipment and workplaces used by the current, living population even though this field is broadly labeled 'anthropometry'. For example if designing personal protective equipment (PPE), such as a coverall, then body circumferences are essential in addition to bony lengths. Circumference data needs to be obtained from living people, specifically from the population for which the design is intended. Similarly, collecting fat folds may be useful for studying fitness or performance of an athlete by sports scientists (and this is also considered to be 'anthropometry'), but these data are not applicable to the design of a coverall. Public health data, such as height and weight, are useful in examining population health. While weight is a very rough indication of possible circumference, by itself it is insufficient to define body size and shape where much more precision is needed for design purposes. Data needs to be fit for purpose. This paper examines all sources of anthropometric data in the Australian context but discusses them in terms of their suitability for engineering and design purposes.

\subsection{Anthropometric data in Australia}

There are anthropometric data available in Australia, however much of these data are proprietary or commercial-in-confidence. Of the publicly available data much is out-of-date or of military origin, not civilian population-based, and thus of limited value when applied to civilian populations. The Australian Bureau of Statistics [2, 3] has collected data that are limited to height and weight that, as discussed above, may be useful for public health purposes, but have limited value for designers. In addition these data are self-reported and while there has been a correction using a validation process, there are acknowledged inaccuracies.

There is anecdotal evidence that the Australian population is changing over time, supporting the view that Australians are getting heavier but not much taller. [6, 3] If this is the case, then it must be accounted for in existing and future workplace and product design.

Other nations have conducted sizing surveys in the last 10 years [5] and these data are often available to Australian designers; however, there is no assurance that these data are relevant to the Australian population. There is a clear need for Australia to collect and maintain an engineering anthropometric database for at least the working population.

This paper describes a pilot research project and its findings that has stimulated discussion in Australia about the need for a national sizing survey.

\section{Method}

This pilot project aimed to collect information from designers who design Australian workplaces or products for use in Australian workplaces, as well as those people who advise designers or write briefs for them. These included government technical staff and ergonomists who evaluate safe design for workplaces. In addition to a literature review of published and grey literature we used two means of obtaining data: a survey of designers, and focus groups and interviews with designers and those who advise them.

\subsection{A survey of designers}

A survey form was developed based on the earlier work of Ward (2006). [14, 15] This asked for demographic information about the designer, including qualifications and experience, as well detailed information about their use of anthropometric data. It also sought information about the type of data that designers would like to have available.

\subsection{Focus groups and interviews}

Two focus groups were conducted; one in Melbourne, Victoria and the other in Adelaide, South Australia. Participants were self-selected from an invitation list made up of designers, and advisers to designers. Each of these areas was well represented and the focus groups were conducted using a semistructured format and interview schedule. [13] Telephone interviews using the same interview schedule were conducted with 12 designers or representatives of various OHS regulators who were unable to attend the focus groups. 


\subsection{A pilot study}

Sizing Up Australia was a pilot study confined to two states of Australia and could not therefore claim to be representative of all Australian designers. Rather it is likely that the sample was biased towards those designers and users of anthropometric data interested in the area of the research, those likely to have a better knowledge of anthropometrics than generally the case. That is, they may represent the best-case scenario.

\section{Findings}

\subsection{Results of the survey}

In all, 32 people responded to the survey (17 men and 15 women); three quarters of the respondents held tertiary qualifications and had worked for more than 10 years in the design industry. Of the respondents $90 \%$ reported that they had used anthropometric data in the last twelve months.

The sample size $n=32$ was too small to reliably group respondents so data were presented in aggregate form and are indicative, rather than representative.

The 32 participants used anthropometric data in the following ways:

- to roughly quantify measurements for their de$\operatorname{sign}(23)$,

- to evaluate user space requirements (21),

- to validate the design profile (15),

- to accurately quantify measurements for the design (12),

- to provide a human shape for an illustration (8),

- for rapid prototyping (5), and

- for other purposes (3).

Respondents rated one-dimensional data (1D) as least useful but admitted that commonly available international 1D data is what they mostly used. They do this because it is available and admitted they questioned its reliability, validity and capacity to represent the current Australian workforce. In the absence of better resources they regarded it as 'better than nothing.' Essentially, most designers used 1D data to determine approximate fit. The other description used by participants was that it was a 'rough guide' to the measurements they would expect in order to affirm what they already believe is logical.

Participants indicated that they would prefer to use three dimensional data (3D) but had little experience with or access to it. They also said they would seek opportunities to learn more, as they feel access to relevant $3 \mathrm{D}$ data for their specific design problems would present new and improved problem-solving opportunities.

\subsection{Results of the focus groups and interviews}

Data gathered from interviews and focus groups were combined with the descriptive (free text) questions on the survey to provide a number of useful case studies from designers that gave insight into the research questions. These can be found in the full report. [13]

In summary, participants reported there were often discrepancies between anthropometric data available to them and the actual measurements of their user group. To resolve these differences, they tended to take their own measurements (usually on very small samples) and conduct verification trials to produce design solutions. This tended to be done opportunistically with whoever was available at the time, thus educators used their students and employers used their employees as the sample.

Participants in the focus groups identified that they, and the majority of designers they know, either do not use anthropometric data at all, or have difficulty in finding any data that would be relevant and reliable to their specific needs. They frequently rely on 'house models' or even themselves, neither of whom may be representative of the intended user population. Sometimes the selection of a house model is intuited from commercial experience and interpreting sales data. The survey highlighted that the use of anthropometric data by Australian designers is relatively unsophisticated; those who use it at all are likely to depend on easily accessible anthropometric data from Europe and the USA. These data are often old and of questionable relevance to the Australian population. Australian data are often proprietary or commercialin-confidence (both civilian and military data) and are thus not available for general use. Some Standards include anthropometric data, but these are often inadequate for designers or are outdated and so have varying validity.

\section{Towards a national sizing survey}

World Engineering Anthropometry Resource (WEAR) [16] meetings were held in Adelaide, South Australia in 2007 and 2011, hosted by Human Fac- 
tors \& Ergonomics Society of Australia inc. (HFESA). HFESA is a professional organization of ergonomists and human factors specialists in Australia [9] with more than 500 members. After the first WEAR meeting, HFESA formed Anthropometry Resource Australia Special Interest Group (ARASIG) [1] in response to the growing interest and concern about the lack of Australian engineering anthropometry. Its aims include the sharing of anthropometric knowledge, making available information including data, tools and techniques, and applications and case studies. By 2011 ARASIG had more than 150 members. In 2009 ARASIG participated in a scoping study for an anthropometric survey in Australia conducted by the National Measurement Institute (NMI). At this stage no NMI report has been made publicly available.

\subsection{Building on Sizing Up Australia}

ARASIG has been lobbying for an Australian sizing survey in line with the recommendations of the Sizing Up Australia research report. [13] Participants in the research observed that that future requirements for anthropometric data of the Australian workforce will need to have different data objectives and parameters than those currently available. In particular, future data will need to be used in a digital environment and designs will need to be suited to a larger range of user sizes than is currently the case, chiefly of those whose body mass is bariatric, i.e., in excess of $120 \mathrm{~kg}$.

Participants commented that they were not confident that the current data set adequately reflects the extremes of the population in Australia, which are often represented by percentiles. In the future, participants may choose not to use percentiles but rather the superior statistical methods such as multivariate case studies that combine the use of appropriate 1D and 3D data. These superior methods require access to individual $1 \mathrm{D}$ and $3 \mathrm{D}$ data as distinct from aggregated data. In addition the anthropometric data needs to be specifically for design and engineering purposes, as discussed above.

Specific requirements are needed for some subgroups of the Australian population. These include bariatric patients in relation to ambulance and hospital environment, and the disabled. Improved data in these areas could help clarify various design requirements, such as facilitate the implementation of the Australian building code.
Sizing Up Australia identified that designers relied on readily available $1 \mathrm{D}$ data sources to tell them about users. In addition, when these data were used they were not always used in a reliable and statistically robust way.

\subsection{What designers need}

Optimally the identified design problems would be avoided by having the correct information to hand during the design and testing phase to enable good design solutions to be prepared in the first place. This can only happen with an up-to-date, relevant, Australian anthropometric database that includes 3D body scans. The database needs to be available at low cost because the design and testing phases are still expensive. A scientific base is needed so designers can verify and fine tune their designs. These data are an investment in the future. They will enable designers to produce safer, better, more thoroughly and scientifically tested well-designed workplaces and products for all Australians.

The development of case studies showing the tools designers could use to incorporate new anthropometric data would assist in the training and dissemination of resources for users. The professional societies, in particular HFESA, ARASIG and WEAR may provide a useful distribution network or conduit for data and tools that could be made available to designers.

\section{Conclusions}

The technology for collecting, analyzing and applying anthropometric data to design has changed significantly in the last decade, but these new technologies, despite being perceived by designers as the most useful, have thus far had limited uptake in Australia. The use of computer-aided anthropometry, such as 3D body scans and computer-aided design, has enhanced the accuracy but also increased the complexity of design. The lack of an Australian Sizing Survey represents a major disincentive for designers to design specifically for Australian workplaces with concomitant concerns for health and safety. This is particularly so in the case of safetycritical designs such as personal protective equipment and machinery design for high-reliability organizations.

Lack of reliable and valid anthropometric data for the Australian population, inadequate infrastructure, and limited application of available data put the de- 
signer in an invidious position. These difficulties are increased when data contained in Standards are conflicting or inaccurate and the Standards are called into legislation, or are a design criterion in contracts. The designer is left with an uncertain level of responsibility; an uncomfortable place to be in an increasingly litigious society.

Anthropometric national sizing surveys of the civilian population including 3D body scan data have been conducted in Japan, France, UK, Netherlands, Canada, Italy, USA, Spain, Taiwan, Korea and Brazil, but not yet Australia. [5] A high quality anthropometric Australian sizing survey, including 3D data, would be a significant infrastructure contribution to Australia. If the raw data were to be freely accessible to the widest possible audience, e.g. designers, applications developers, ergonomists, government etc., this would lead to some very good outcomes for Australia. Clever design - get it right the first timewould save time and money in design solutions and support the building of Australian innovation and research capability. This in turn would support the increased productivity necessary if Australia's manufacturing industry is to compete against low cost global markets. Manufacturing onshore is important in these times of global financial crisis as it's been shown that countries with a strong manufacturing base are faring better. [12]

For engineering design purposes high quality Australian anthropometric data would define the size and shape of Australians and represent the diversity of the population (migration, ageing and increased weight). This would not only add sizing, design, simulation, case selection, digital modeling and training capacity for designers to design and innovate for Australian markets, increasing efficiency and gaining competitive advantage, but would also improve the safety of our workplaces.

\section{Acknowledgements}

Thanks to the Australian Safety and Compensation Council (now Safe Work Australia) for funding this research. We thank Dr Stephen Cox for assisting with statistical analysis.

\section{References}

[1] Anthropometry Resource Australia Special Interest Group (ARASIG) http://www.ergonomics.org.au/sigs/arasig.aspx (accessed September 2011).
[2] Australian Bureau of Statistics. 4359.0 - How Australians measure up, 1995. (Released 1998). Retrieved 22/02/2008, 2008, from http://www.abs.gov.au/AUSSTATS/abs@.nsf/ productsbyCatalogue/B66CED7E47B041B5CA2570B50017 FFB8?OpenDocument p 11 (accessed September 2011).

[3] Australian Bureau of Statistics, 4842.0.55.001 - Overweight and Obesity in Adults in Australia: A Snapshot, 2007-08. (released 2001) http://www.abs.gov.au/ausstats/abs@.nsf/ Products/73E036F555CE4C11CA25789C0023DAF8?opendocume nt (accessed September 2011).

[4] S. Blackwell, K.M. Robinette, H.A.M. Daanen, M. Boehmer, S. Fleming, S. Kelly, T. Brill, D. Hoeferlin and D. Burnsides, Technical report ARFL-HE-WP-TR-2002-0173, United States Air Force Research Laboratory, Civilian American and European surface anthropometry resource (CAESAR), Final Report 2, Warrendale, PA.

[5] H. Daanen, 3D data collection methods. World Engineering Anthropometry Resource, WEAR Conference, Tokyo, Japan, (2008).

[6] M. Henneberg and D. Veitch, National Size and Shape Survey of Australian, Kinanthreport 2003: Newsletter of the International Society for the Advancement of Kinanthropometry. 16 (2003), 34-39.

[7] H. T. E. Hertzberg, The Conference on Standardization of Anthropometric Techniques and Terminology, American Journal of Physical Anthropology, Volume 28, Issue 1 , January 1968 , pp. 1-16.

[8] A. Hrdlička, 1952 Practical Anthropometry, 4th Edition, T. D. Stewart, Editor, The Wistar Institute of Anatomy and Biology, Philadelphia. Reprints the "Report of the commission appointed by the fourtheenth International Congress of Anthropology and Archaeology at Geneva (1912), to supplement the work commenced by the Thirteenth Congress in the session at Monaco (1906); translated by W. L. H. Duckworth. The Anthropological Laboratory of the University, New Museums, Cambridge, 1912.

[9] Human Factors and Ergonomics Society of Australia Inc (HFESA) http://www.ergonomics.org.au/ (accessed September 2011).

[10]R. Martin, Lehrbuch der Anthropologie, 3d Edition, K. Saller, Editor. Gustav Fischer Verlag, Stuttgart, (1957).

[11]K. Norton, Nancy Whittingham, Lindsay Carter, Deborah Kerr, Christopher Gore and Michael Marfell-Jones, International Society for the Advancement of Kinanthopometry (ISAK), 2001.

[12] G. Roos What does the future hold for manufacturing in South Australia? Public lecture at the Adelaide Town Hall, 27 September 2011, http://www.thinkers.sa.gov.au/Thinkers/Roos/default.aspx (accessed September 2011)

[13]D. Veitch, D. Caple and V. Blewett, Sizing Up Australia: How contemporary is the anthropometric data Australian designers use? Research Report http://www.safeworkaustralia.gov.au/ (2009).

[14] S. Ward, Designers and users: A survey of user research methods employed by Australian industrial designers, unpublished thesis, Master of Science (Research), University of New South Wales (2006).

[15] WEAR Strategic Plan 2008. WEAR Conference Handbook, Proceedings of the WEAR Conference Adelaide, South Australia, February 2007. Human Factors and Ergonomics Society of Australia Inc. NSW WEAR (2008) World Engineering Anthropometry Resource http://wear.io.tudelft.nl/ (accessed June 2008).

[16]World Engineering Anthropometry Resource http://wearanthro.org (accessed September 2011). 